\title{
Comparison of moisture distribution along radial direction in a log cross section of heartwood and mixed sapwood and heartwood during radio- frequency/vacuum drying
}

\begin{abstract}
The purpose of this study was to compare the distribution of moisture contents (MCs) along the radial direction during radio-frequency/vacuum $(\mathrm{RF} / \mathrm{V})$ drying of $\log$ cross sections of heartwood (HLC) where sapwood was removed from a green log cross section and log cross section of mixed sapwood and heartwood (MLC) prepared with debarked logs of Japanese larch (Larix leptolepis) and locust (Robinia pseudoacacia). For Japanese larch, an even distribution of $\mathrm{MC}$ was observed over the entire cross section in HLC not only at the initial stage of drying but also up to the completion of drying. Furthermore, the moisture gradient between the outermost slice and the adjacent inner slice was more gradual compared with that in MLC. For locust, the moisture gradient between the outermost slice and the adjacent inner slice became severe as drying progressed. It decreased after reaching the maximum during the middle stage of drying but continued until the late stage of drying. Furthermore, despite the fact that the average initial MC of mixed slice within MLC was higher compared with that in heartwood slice, this trend reversed immediately after drying started. It was suggested that the possibility of formation of border checking would be high during drying the MLC, since it would be so complicate that the sapwood and heartwood reach fiber saturation point together because of differences in their green MCs and permeability between them.
\end{abstract}

Key words Japanese larch · Locust · Moisture gradient . Slice $\cdot$ Border checking $\cdot$ Permeability

N.-H. Lee $(\bowtie) \cdot C$. Li · J.-H. Choi · U.-D. Hwang

Department of Wood Science and Technology, College of

Agriculture and Life Science, Chonbuk National University, Chonju,

Chonbuk 561-756, Republic of Korea

Tel. +82-63-270-2623; Fax +82-63-270-2631

e-mail: enamho@chonbuk.ac.kr

\section{Introduction}

Because the moisture gradient can be maintained gradually along the longitudinal direction due to the pressure gradient between the inner wood and the atmosphere, and the reverse temperature gradient between the shell and core when radio frequency/vacuum ( $\mathrm{RF} / \mathrm{V})$ drying is performed in $\log$ cross sections, heart checks can be prevented very effectively. ${ }^{1-4}$ Furthermore, the ability to prevent V-shaped cracks is also significant because compared with conventional kiln drying, the drying in a RF/V kiln is achieved at a lower temperature and the difference in shrinkage between the tangential direction and radial direction can be lowered. ${ }^{5,6}$ Other benefits include the fact that the workability of stacking log cross sections that are cylindrical and irregular in some cases can be improved significantly because solid pile or dead stacking is applied in a RF/V kiln and the inherent color of the log cross sections can be maintained.

However, because the sapwood and heartwood within a log cross section can show significant differences according to the major controlling factors of drying characteristics during RF/V drying, i.e., the green moisture content (MC) and permeability. Some studies reported that a moisture gradient can occur in the border between the sapwood and heartwood. ${ }^{7,8}$ This moisture gradient is severe in some species so that checks can occur at the border. The so-called border check can lead to a $\mathrm{V}$-shaped crack in the late stages of drying when differential shrinkage stress is concentrated at the border. ${ }^{7}$ Hence, it is very important, but not easy, to prevent building of tangential stress in tension by maintaining an even distribution of MC between the sapwood and heartwood within a log cross section during the hygroscopic stage. In general, the MC in the heartwood of softwoods is significantly lower compared with that in the sapwood. Thus, it does not necessarily mean that the heartwood would reach the fiber saturation point (FSP) when the heartwood shows poor permeability despite coming nearer to the FSP at the initial stage of drying. In addition, because the sapwood can reach the FSP earlier compared with the heartwood when the permeability of the heartwood is poor, 
it is necessary to delay moisture evaporation from the sapwood with higher moistures by end-covering with paper and end-wrapping with aluminum foil or plastic film. ${ }^{3,49}$ However, it is very difficult to decide on the treatment and the level of treatment because these treatments are not only burdensome but also could lead to the opposite effect when the treatments are excessive. Jung et al. ${ }^{10}$ proposed to completely remove the sapwood, the cause of border checking, from a log cross section before starting of a drying process in species with a small portion of sapwood such as in Japanese larch, locust, and Chinese mahogany. Studies on this subject are lacking. Furthermore, the removal of sapwood could lead to the formation of a moisture gradient along the radial direction according to moisture evaporation through the tangential surface of the log cross section during drying, eventually leading to a V-shaped crack.

This study was carried out to compare the moisture distribution along the radial direction in a log cross section of heartwood (HLC), from which sapwood was removed from the green log cross section, and a log cross section of mixed sapwood and heartwood (MLC) during RF/V drying. The samples were prepared with debarked logs of Japanese larch (Larix leptolepis) and locust (Robinia pseudoacacia). This work allowed the investigation into the prevention of checking formation by removal of sapwood from a log cross section.

\section{Materials and methods}

Preparation of log cross sections

Several logs of Japanese larch (softwood) and locust (hardwood) were purchased from the market. The logs contained a small portion of sapwood, were not eccentric and were $2.1 \mathrm{~m}$ long. The logs from each species were divided into MLC specimens with a small diameter and HLC specimens with a large diameter. The ends of each log were cut off $(20 \mathrm{~cm})$, and $30-\mathrm{mm}$ thick $\log$ cross sections were cut for the drying test. Log cross sections (10-mm thick) for green MC measurement were prepared from both ends of each log cross section of $30 \mathrm{~mm}$ thickness. Three log cross sections among them were taken from both ends and the middle of each $\log$ and were then used for investigating the radial distribution of green MC.

Each log cross section for the drying test was debarked by circumferential band sawing. The sapwood was removed completely in the HLC specimens so that only the heartwood remained at the end surfaces. The MLC specimens were processed so that the sapwood content was as high as possible within the given diameter (Fig. 1). Finally, the tangential surfaces of the test samples were painted with epoxy resin so that moisture evaporation could occur from the tangential surface. For the HLC and MLC specimens, 32 sections from Japanese larch and 24 sections from locust were prepared, respectively. The final diameters of the log cross sections were set at $24 \mathrm{~cm}$ for Japanese larch and $20 \mathrm{~cm}$ for locust. The initial MC in Japanese larch HLC and MLC specimens were $42.8 \%-46.3 \%$ and $51.8 \%-61.2 \%$, respec-
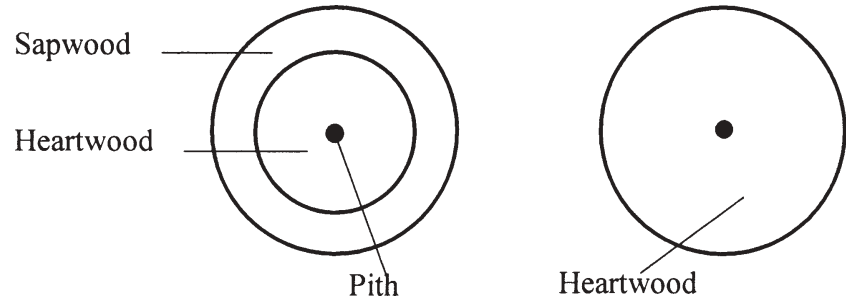

Fig. 1. Schematics of log cross section of mixed sapwood and heartwood (MLC) (left) and log cross section of heartwood (HLC) (right) for the radio frequency/vacuum $(\mathrm{RF} / \mathrm{V})$ drying test

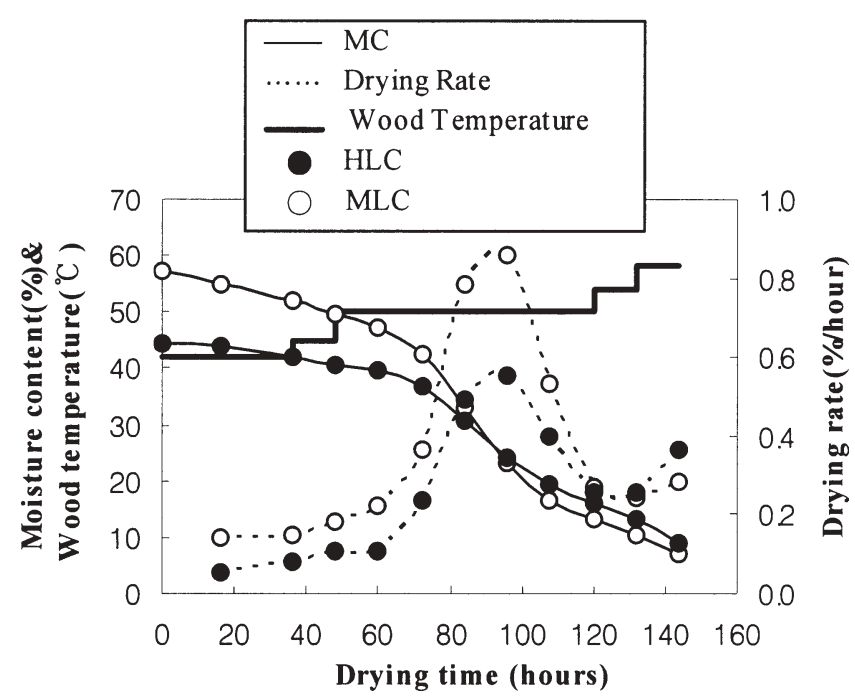

Fig. 2. Moisture contents and drying rates as a function of drying times during RF/V drying of Japanese larch log cross sections

tively, and those in locust HLC and MLC specimens were $54.5 \%-59.6 \%$ and $42.4 \%-46.0 \%$, respectively.

\section{$\mathrm{RF} / \mathrm{V}$ drying test}

The RF/V drying kiln ${ }^{7}$ was $274 \mathrm{~cm}$ long, $102 \mathrm{~cm}$ wide, and $40 \mathrm{~cm}$ high. The RF generator had a maximum output of $7 \mathrm{~kW}$, the frequency was set at $13 \mathrm{MHz}$, and drying was performed by turning the machine on for $8 \mathrm{~min}$ and off for 2 min. Each log cross section of Japanese larch and locust was tested according to each run. Log cross sections for RF/ $\mathrm{V}$ drying test were solid-stacked five high between a ground electrode plate on top and a RF charge electrode plate in the middle, and dummy stacking was performed using green log cross sections between the RF charge plate and a bottom ground plate. HLC stacked layers and MLC stacked layers were placed adjacent to each other.

In order to control wood temperature during RF/V drying, a platinum sensor sheathed in a teflon tube was inserted deeply toward the pith in the middle at the log cross section thickness, and sealed with silicon. During RF/V drying of Japanese larch log cross sections, the wood temperature started at $42^{\circ} \mathrm{C}$ and increased to the final temperature of $58^{\circ} \mathrm{C}$ (Fig. 2). For the locust log cross sections, RF/V drying was performed between $43^{\circ} \mathrm{C}$ and $54^{\circ} \mathrm{C}$ (Fig. 3). Atmospheric pressure in the $\mathrm{RF} / \mathrm{V}$ kiln during drying was $5.3-8 \mathrm{kPa}$. 


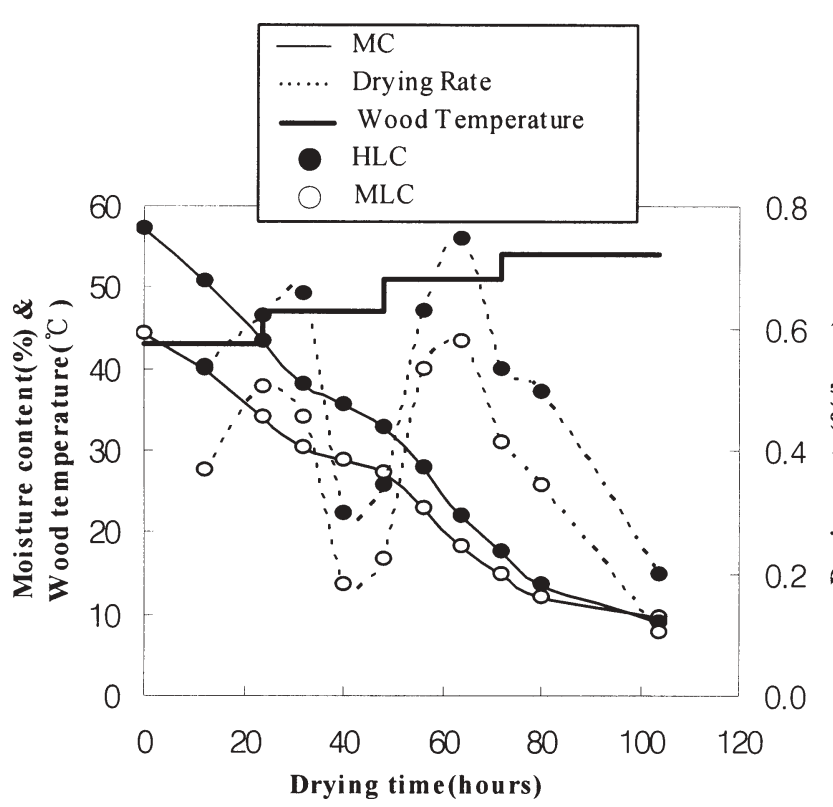

Fig. 3. Moisture contents and drying rates as a function of drying times during $\mathrm{RF} / \mathrm{V}$ drying of locust log cross sections

Radial distribution of MC within a log cross section during RF/V drying

The RF/V drying kiln was stopped during drying at appropriate intervals, and the weight of each log cross section was measured to determine the MC during RF/V drying. Each time, each HLC and MLC without checks and V-shaped cracks among the log cross sections stacked in the second, third, and fourth layers was obtained to determine the MC distribution along the radial direction by selecting those log cross sections representing 5\%-10\% lower MC compared with those $\log$ cross sections taken in the previous step. The area where specimens were removed was filled by placing a dummy stack section being dried in the bottom part, and an air-dried log section of the same species was placed in the site of dummy stack section removed.

Each log cross section for the MC distribution along the radial direction was cut into circumferential slices that were $4 \mathrm{~mm}$ thick in the radial direction using a specially designed jig and bandsaw for woodworking (Fig. 4). The MC of each slice was determined using the oven-dry method. ${ }^{11}$ Finally, the MCs were plotted with the relative location along the radial direction of the log cross section.

The average $\mathrm{MC}$ and drying rate were analysed for each group after dividing each slice cut from MLC into a heartwood slice, a sapwood slice, and a mixed heartwood and sapwood slice (mixed slice). However, pure sapwood slices could not be obtained from locust log cross sections because the amount of sapwood was very low and the border between the heartwood and sapwood was not a regular circle.

Among the sections stacked in the top part in the RF/V kiln, the average $\mathrm{MC}$ and the average drying rate during $\mathrm{RF} / \mathrm{V}$ drying was calculated according to drying time from $\log$ cross sections other than those taken to investigate the $\mathrm{MC}$ distribution along the radial direction.

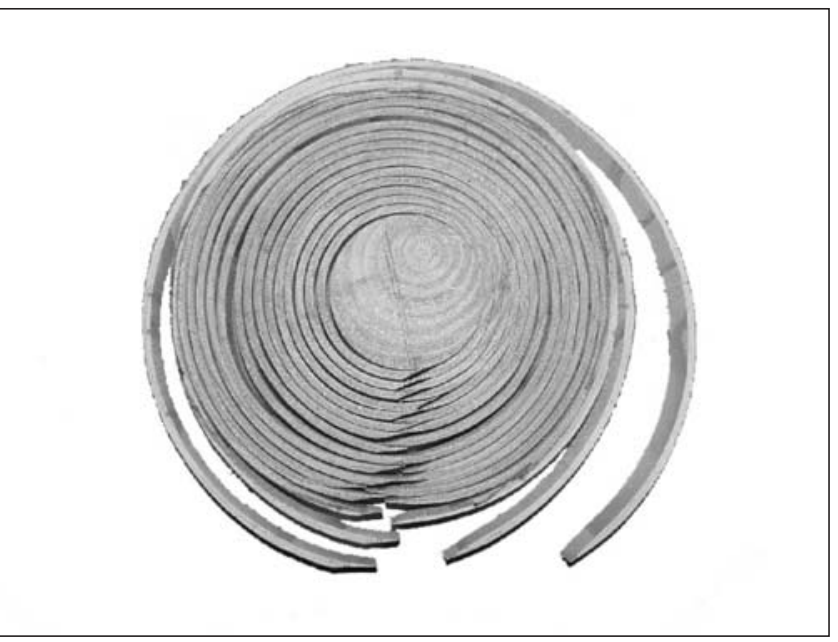

Fig. 4. Circumferential slices cut from a larch log cross section

\section{Results and discussion}

Drying curves and drying rate curves

Figures 2 and 3 show $\mathrm{MC}$ and drying rate as a function of drying time during $\mathrm{RF} / \mathrm{V}$ drying of $\log$ cross sections of Japanese larch and locust, respectively.

In the case of Japanese larch log cross sections, the initial MC of $44.7 \%$ for HLC specimens reduced to $8.8 \%$ during $144 \mathrm{~h}$, whereas the initial MC of $57.2 \%$ for MLC specimens dropped to $7.1 \%$, showing the average drying rate of $0.35 \% /$ h. This was somewhat faster than $0.25 \% / h$ for HLC. Because the green MC was relatively high in MLC specimens, which contains the sapwood having fair permeability, because driving forces such as the promotion of capillary flow of moisture obtained in a RF/V kiln might be successfully reflected. ${ }^{4}$ In other words, the percentage of sapwood would play a decisive role in the difference in average drying rate of HLC and MLC. This role is more clearly shown with the findings that the sapwood showed a drastic decrease in $\mathrm{MC}$ at the initial stage of drying but did not show a significant difference from that in the heartwood after the MC of the sapwood reached a similar level as that in the heartwood, as shown in Figs. 5 and 6. On the other hand, for each increase in wood temperature immediately after starting drying, the drying rate increased continually in all HLC and MLC specimens to the maximum wood temperature of $50^{\circ} \mathrm{C}$ so that the rate was $0.86 \% / \mathrm{h}$ in MLC and was $0.55 \% / \mathrm{h}$ in HLC. Later, the drying rate decreased drastically in the same wood temperature range, maybe because the driving force obtained in a RF/V kiln weakens when the average MC of each log cross section becomes lower than the FSP. ${ }^{2,12}$

In the case of locust log cross sections, the drying time from green to $9 \%-10 \% \mathrm{MC}$ was $104 \mathrm{~h}$. The average drying rates for HLC and MLC were $0.46 \% / \mathrm{h}$ and $0.33 \% / \mathrm{h}$, respectively, indicating that HLC had the faster drying rate during the overall drying period. In the case of locust, no significant difference was observed in the green MC between the heartwood and sapwood, but also the portion of sapwood would 

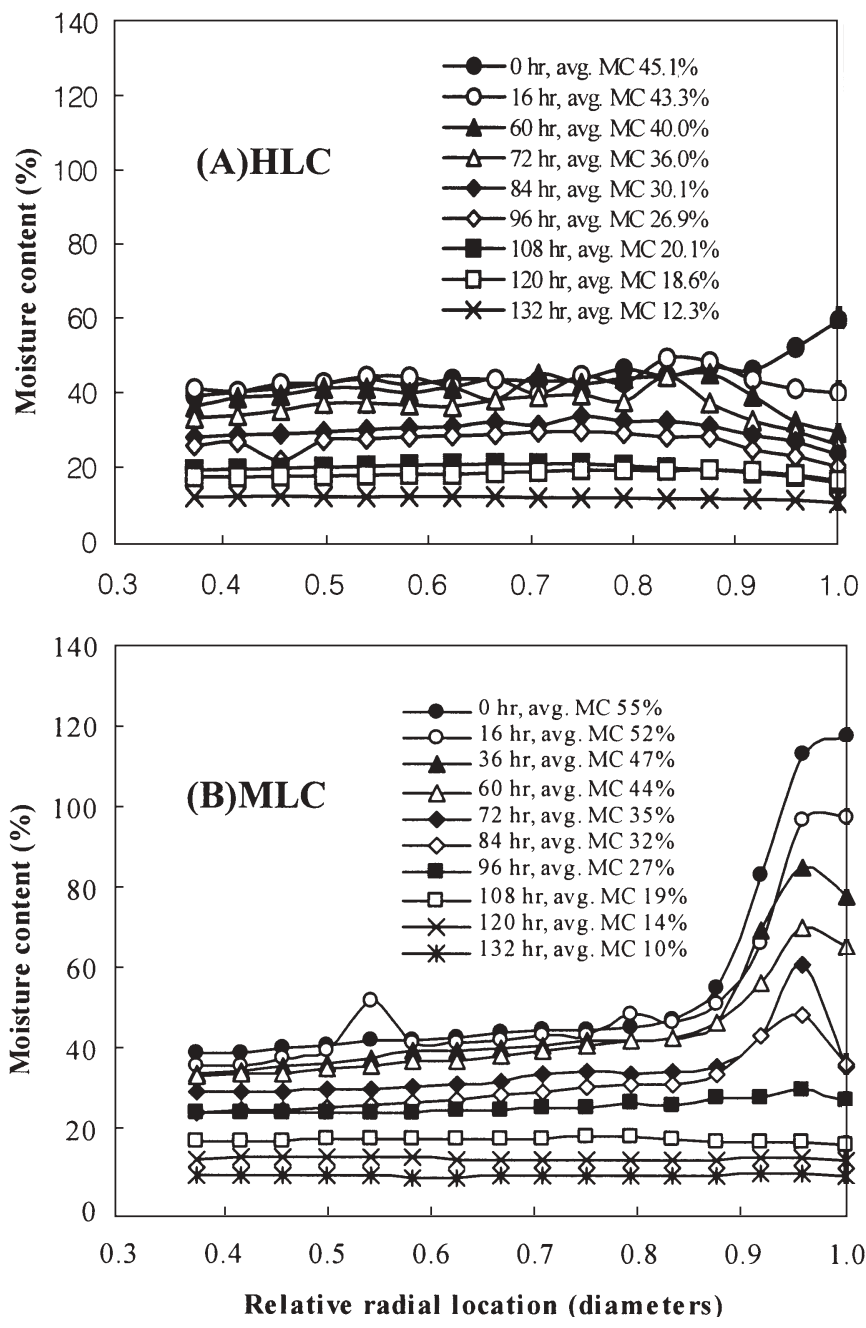

Fig. 5. Radial distribution of moisture contents within a Japanese larch $\log$ cross section during RF/V drying

be low because most of sapwood area was removed when circumferential bandsawing the irregular trunk shape. Therefore, the contribution by sapwood to the overall drying characteristic of MLC was small. Drying rates increased sharply after increasing the wood temperature to $47^{\circ} \mathrm{C}$ and $50^{\circ} \mathrm{C}$, and decreased drastically after the average $\mathrm{MC}$ neared the FSP, regardless of wood temperature (Fig. 3).

Distribution of $\mathrm{MC}$ along the radial direction within a Japanese larch log cross section

Figure 5 shows MCs along the radial direction from the center of HLC and MLC of Japanese larch during drying. The green MC of MLC was the highest at the outermost slice at $118.5 \%$, decreased sharply toward the pith until 0.88 diameters $(48.5 \%)$, and then decreased gradually to around $40 \%$. This result was observed because more of the portion of sapwood with high moisture was in the outermost slice, and the slice cut from the inner part of 0.88 diameters contained more heartwood having low moisture. This result was similar to the result reported by Kang et al. ${ }^{7}$

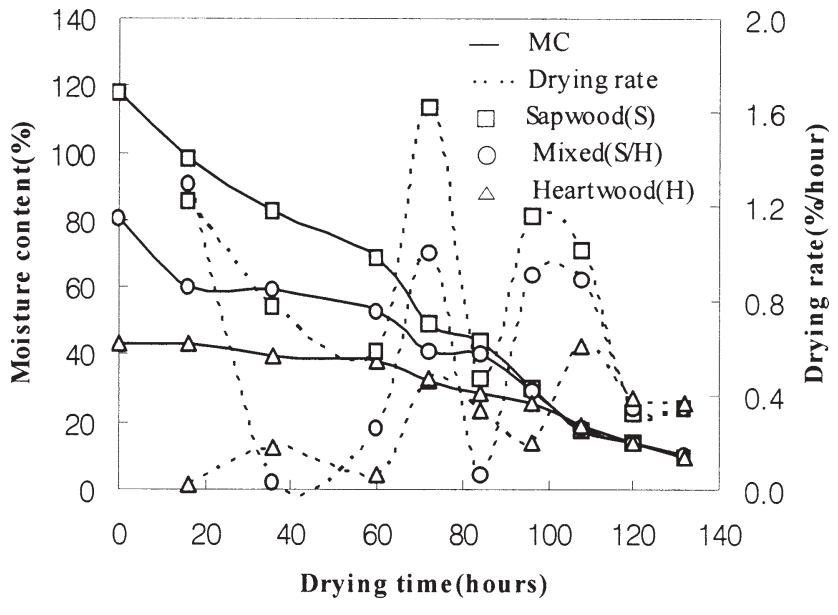

Fig. 6. Average moisture contents and average drying rates of circumferential slices cut from sapwood, mixed wood, and heartwood within a MLC of Japanese larch

The MC decreased drastically in the sapwood located in the outermost slice in MLC as drying progressed, whereas the rate of MC decrease in the inner heartwood was very low, eventually leading to the similar trend until the end of drying after the distribution of MC became uniform at $27 \%$. This trend could be interpreted as resulting from the fact that even if the green $\mathrm{MC}$ was very high in the sapwood compared with the heartwood, permeability was fair in the sapwood so that water could be removed actively above the hygroscopic range and the contribution of permeability on flow rate of water became low in the low MC range. The possibility of border checks occurring would not be high even if no treatment was performed on Japanese larch log cross sections. However, the moisture gradient between the outermost slice and the adjacent inner slice became severe with time so that the maximum moisture gradient between the two slices became $12.3 \%$ at $72 \mathrm{~h}$ (average MC of $35 \%$ ), showing a difference from the distribution of MC of nondebarked log cross sections. ${ }^{7}$ Thus, moisture evaporation was active from the tangential surface during drying because the outer slice of the debarked MLC was surrounded by the sapwood. Nonetheless, the moisture gradient became gentler and gentler from that time and almost disappeared when the average MC reached $27 \%$ after $96 \mathrm{~h}$ of drying time, inducing no checking in the tangential surface.

Although the green MC of HLC was somewhat high at $59.9 \%$ in the outermost slice, a relatively stable MC distribution was seen in the range between $39.2 \%$ and $46.6 \%$ starting at 0.92 diameters from the core. Furthermore, an even moisture gradient was observed over the entire cross section after drying progressed, indicating that tangential stress of tension due to the moisture gradient along the radial direction during drying could be prevented. This result was obtained because the entire cross section of HLC was composed of heartwood with similar green MC and permeability. On the other hand, the moisture gradient formed between the outermost slice and the adjacent inner slice was more gradual compared with MLC, and the maximum point of moisture gradient was also closer to the pith at 0.83 diameters. 
Because HLC was surrounded by the heartwood with low moisture content and poor permeability, the flow rate of water along the radial direction and the rate of moisture evaporation through the tangential surface would be low compared with MLC. Upon the completion of drying, HLC and MLC both showed an even distribution of moisture content along the entire sections, suggesting no residual stress due to moisture gradient along the radial direction.

Figure 6 shows the average MC and average drying rate of sapwood slices, mixed heartwood and sapwood slices (mixed slices) and heartwood slices as a function of drying time. The initial MC was $117.9 \%$ in sapwood slices, $80.5 \%$ in mixed slices, and $43.3 \%$ in heartwood slices, showing about a difference of $37 \%$ MC between the sapwood slices and mixed slices and between mixed slices and heartwood slices. However, the difference became gradual as drying progressed, and then it was very small at the average MC of about $18 \%$ after $96 \mathrm{~h}$ of drying time. This is because the driving force for moving free water in a RF/V kiln is reduced in the heartwood slices and the mixed slices with low initial MC and poor permeability. The drying rate, except at the late stage of drying, was fastest in sapwood slice in most drying steps, followed by mixed slice and heartwood slice with the average drying rate of each slice being $0.84 \% / \mathrm{h}, 0.57 \% / \mathrm{h}$, and $0.29 \% /$ $\mathrm{h}$, respectively. The average drying rates of sapwood slice and mixed slice were about 2.9 times and 2 times faster than the drying rate of heartwood slice, respectively.

The removal of sapwood from a log cross section would be effective in preventing formation of border checking and checking on the tangential surface by maintaining the moisture gradient along the radial direction at a much gentler pace in case of Japanese larch log cross sections. However, it is suggested that even in MLC, the risk of checking during drying would be low because the moisture gradient along the radial direction, including the moisture gradient between the heartwood and sapwood, was almost lost in the hygroscopic range. Further investigation is needed to secure direct evidence by examining the distribution of tangential strain during drying. Furthermore, consideration should be given to the fact that waste could be reduced because the removal of the sapwood is not necessary in MLC.

Distribution of MC along the radial direction within a locust log cross section

Figure 7 shows MCs along the radial direction from the center of HLC and MLC of locust during drying. The initial MC of MLC was very even between $39.4 \%$ and $45.9 \%$, and similar distribution was seen as drying progressed, showing a significant difference from Japanese larch MLC. This may be because not only the differences in the green MCs between the heartwood and sapwood of locust were not high but also the effect of permeability of sapwood was less on drying characteristics of log cross sections due to low percentages of sapwood in the MLC prepared in this study. The moisture gradient built up between the outermost slice and the adjacent inner slice became more severe with drying in which the maximum gradient was $7.2 \%$ when the average MC was $33 \%$ after $24 \mathrm{~h}$ of drying and decreased later on.
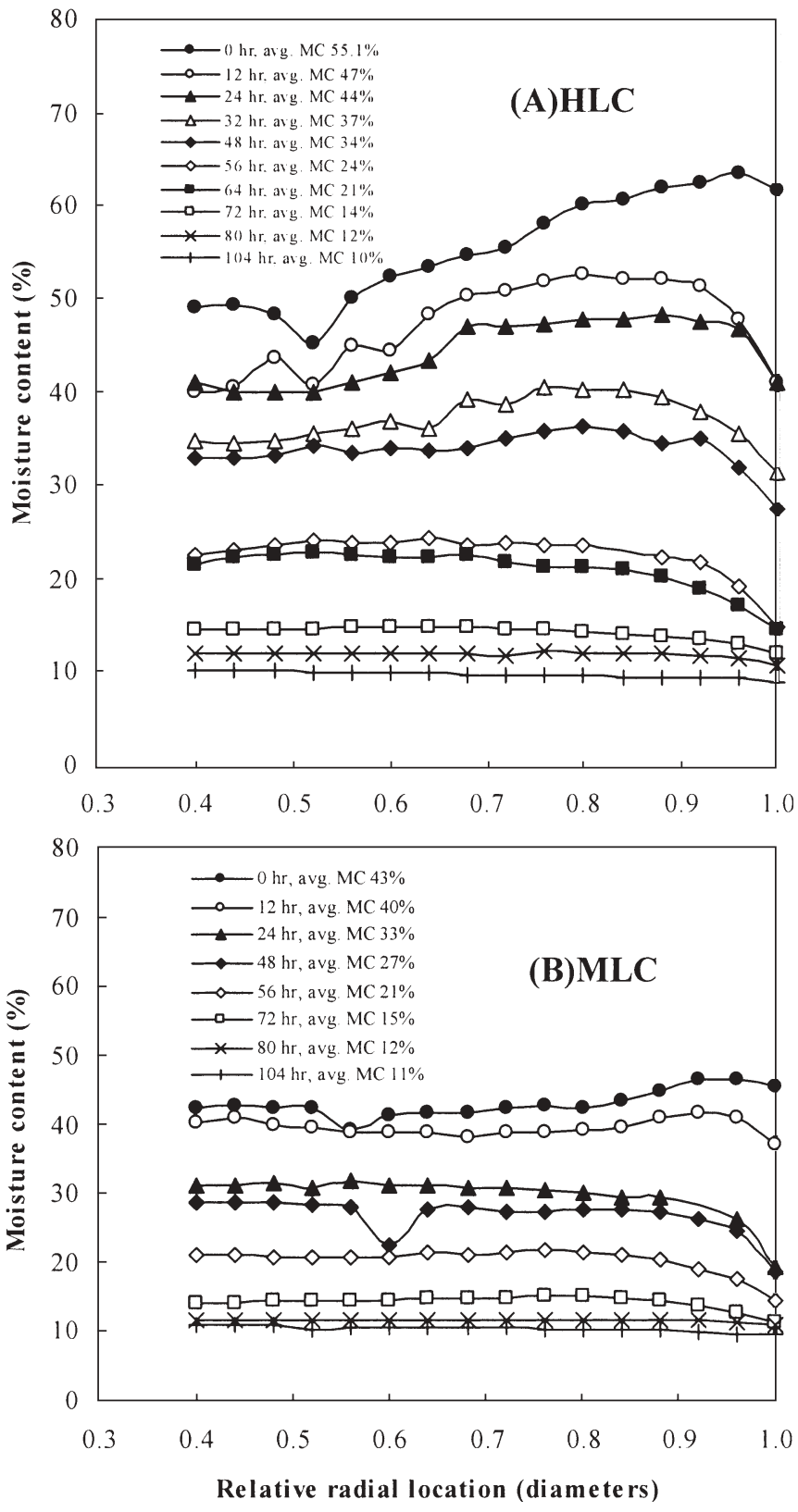

Fig. 7. Radial distribution of moisture contents within a locust log cross section during RF/V drying

However, the moisture gradient was maintained at $2.5 \%$ between the two slices even when the average MC was $15 \%$ after $72 \mathrm{~h}$ of drying. In other words, although a very gradual moisture gradient was seen compared with that in Japanese larch MLC, the gradient existed for a longer time and was steeper in locust in the range of low moisture content, suggesting the possible formation of high tangential stress of tension that could induce checks on the tangential surface.

A similar distribution of MC was seen in HLC over the entire drying period so that no different result was observed by removing the sapwood before drying. However, a significant drying stress would be induced at the border between the heartwood and sapwood if more sapwood was present because the difference in drying rates during the early dry- 


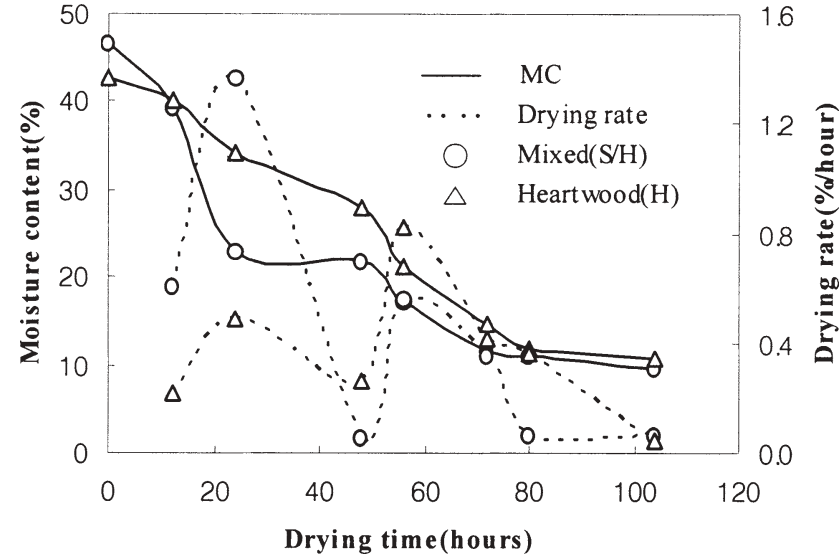

Fig. 8. Average moisture contents and average drying rates of circumferential slices cut from sapwood, mixed wood, and heartwood within a MLC of locust

ing stage between mixed slice and heartwood slices was large as shown in Fig. 8. The average initial MC of mixed slice within MLC was $46.7 \%$, which was about $4 \%$ higher than that in heartwood slice. However, this trend reversed immediately after drying started in which the average MC of mixed slice was about $11 \%$ lower after $24 \mathrm{~h}$ of drying. This trend continued with a $3 \%$ difference between heartwood slice and mixed slice at the average MC of $15 \%$. This means that green $\mathrm{MC}$ and permeability between the heartwood and sapwood of locust do not balance each other so that the heartwood and sapwood pass through the FSP together. Thus, the possibility of the formation of border checking would be very high when the heartwood and sapwood exist within the same log cross section as in the case of $\log$ cross section with bark, as found in many cases in the industrial field. Therefore, it would be desirable to remove the sapwood and dry the log cross sections of locust, rather than trying to obtain log cross sections with bark attached. Consideration should be given to the fact that the loss of volume would not be significant in locust even if the sapwood was removed because the amount of sapwood is very low. Residual drying stress due to moisture gradient would not be significant in locust because findings show an even distribution of moisture content along the entire cross section upon the completion of drying.

\section{Conclusions}

For log cross sections of Japanese larch, an even distribution of MC was observed over the entire cross section in HLC not only at the initial stage of drying but also up to the completion of drying. Furthermore, the moisture gradient between the outermost slice and the adjacent inner slice was more gradual compared with that in MLC. However, the possibility of checking formation in MLC would be low, because the moisture gradient between the sapwood and heartwood became very gentle when below the hygroscopic range.

In case of log cross section of locust, HLC and MLC showed a relatively stable distributions of MC throughout the drying period. However, the moisture gradient between the outermost slice and the adjacent inner slice became severe as drying progressed. It decreased after reaching the maximum during the middle stage of drying but continued until the late stage of drying. Furthermore, despite the fact that the average initial MC of mixed slice within MLC was higher compared with that in heartwood slice, this trend reversed immediately after drying started. It was suggested that the possibility of formation of border checking would be high during drying the MLC, because of the complication in which the sapwood and heartwood reach FSP together because of differences in their green MCs and the permeability between them.

Almost no moisture gradient was present along the radial direction in HLC and MLC of Japanese larch and locust upon the completion of drying.

Acknowledgments This study was supported by the Korean Science and Engineering Foundation.

\section{Referencess}

1. Kanagawa Y, Hayashi K, Yasuzima M (1992) Improvement of dryability by local steam explosion for Japanese cedar. Proceedings of 3rd IUFRO International Wood Drying Conference, Vienna, Austria pp 269-276

2. Avramidis S, Liu F, Neilson BJ (1994) Radio-frequency/vacuum drying of softwoods: drying of thick western redcedar with constant electrode voltage. Forest Prod J 44:41-47

3. Lee NH, Hayashi K, Jung HS (1998) Effect of radio-frequency/ vacuum drying and mechanical press-drying on shrinkage and checking of walnut log cross sections. Forest Prod J 48:73-79

4. Lee NH, Hayashi K (2000) Effect of end-covering and low pressure steam explosion treatment on drying rate and checking during radio-frequency/vacuum drying of Japanese cedar log cross sections. Forest Prod J 50:73-79

5. Harris RA, Taras MA (1984) Comparison of moisture content distribution, stress distribution, and shrinkage of red oak lumber dried by a radio-frequency/vacuum drying process and a conventional kiln. Forest Prod J 34:44-54

6. Lee NH, Jung HS (2000) Comparison of shrinkage, checking, and absorbed energy in impact bending of Korean ash squares dried by a radio-frequency/vacuum process and a conventional kiln. Forest Prod J 50:69-72

7. Kang W, Lee NH, Choi JH (2001) A radial distribution of moistures and tangential strains within a larch log cross section during radio-frequency/vacuum drying. Proceedings of 7 th International IUFRO Wood Drying Conference, Tsukuba, Japan pp 376-381

8. Kang W, Lee NH (2002) Mathematical modeling to predict drying deformation and stress due to the differential shrinkage within a tree disk. Wood Sci Technol 36:463-476

9. Kubler H (1974) Drying tree disks simply and without defects. Forest Prod J 24:33-34

10. Jung HS, Lee NH, Kang CW, Lee JH, Kang W, Park MJ (1999) Development of vacuum-press drying technology for structural softwood lumbers and woods for special goods (in Korean). Report of Korean Ministry of Agriculture and Forestry, Korea pp 149-173

11. Choi JH (2002) Determination of a radial distribution of tangential strains within a $\log$ cross section by a circumferential slicing method (in Korean). Masters thesis, Chonbuk National University, Korea pp 4-23

12. Liu F, Avramidis S, Zwick RL (1994) Drying thick western hemlock in a laboratory radio-frequency/vacuum dryer with constant and variable electrode voltage. Forest Prod J 44:71-75

The publication of this article was made possible by an Emachu Research Fund. The authors are greatful for the fund. 